\title{
Refining the ideas of "ethnic" skin
}

Vicente Torres
Adilson Costa $^{3}$
Patricia Troielli $^{5}$

DOI: http:/ /dx.doi.org/10.1590/abd1806-4841.20174846

\author{
Maria Isabel Herane ${ }^{2}$ \\ Jaime Piquero Martin ${ }^{4}$
}

\begin{abstract}
Skin disease occur worldwide, affecting people of all nationalities and all skin types. These diseases may have a genetic component and may manifest differently in specific population groups; however, there has been little study on this aspect. If population-based differences exist, it is reasonable to assume that understanding these differences may optimize treatment. While there is a relative paucity of information about similarities and differences in skin diseases around the world, the knowledge-base is expanding. One challenge in understanding population-based variations is posed by terminology used in the literature: including ethnic skin, Hispanic skin, Asian skin, and skin of color. As will be discussed in this article, we recommend that the first three descriptors are no longer used in dermatology because they refer to nonspecific groups of people. In contrast, "skin of color" may be used - perhaps with further refinements in the future - as a term that relates to skin biology and provides relevant information to dermatologists.
\end{abstract}

Keywords: Acne vulgaris; Genetics; Dermatology

\section{INTRODUCTION}

Skin disease is a global concern, yet little is known about acne from a population-based perspective. ${ }^{1}$ The idea that racial or genetic differences between groups have a relation with health or disease has been supported by sequencing of the human genome and the ongoing international effort to catalog common haplotypes in various populations. ${ }^{2,3,4}$ With this active research, it is time to examine the complex relation between genetic research and the concepts of race, ethnicity, and ancestry and disease in dermatology. ${ }^{1,4}$

\section{THE ORIGINS OF HUMAN BEINGS}

Existing data suggest that humans first appeared in Africa and later colonized Eurasia and the Americas., ${ }^{5,6}$ Studies of mitochondrial DNA, the $\mathrm{Y}$ chromosome, portions of the $\mathrm{X}$ chromosome, and many (though not all) autosomal regions support the "Out of Africa" account of human history, in which anatomically modern humans appeared first in eastern Africa and then migrated throughout Africa and into the rest of the world. ${ }^{7-11}$ During this migration, there was little or no interbreeding between modern humans and the archaic populations (Neanderthal or Cro-Magnon) they gradually replaced. ${ }^{12,13}$

The observation that most genes studied to date coalesce in African populations points toward the importance of Africa as the source of most modern genetic variation, perhaps with some subdivision in the ancestral African population. ${ }^{11}$ Sequence data for hundreds of loci from widely distributed worldwide populations eventually may clarify the population processes associated with the appearance of anatomically modern humans, as well as the amount of gene flow among modern humans since then. ${ }^{10,14}$ In general, however, the short duration of common ancestry and continual gene flow among human groups has limited genetic differentiation in our species. Some commentators have argued that patterns of variation provide a biological justification for the use of traditional racial categories. ${ }^{15}$ They note that the continental genetic clustering corresponds roughly with the division of human beings into sub-Saharan Africans, Europeans, Western Asians, Northern Africans, Eastern Asians, Polynesians and other inhabitants of Oceania and Native Americans (Amerindians)..$^{15}$

Other observers disagree, saying that the same data belies traditional notions of racial groups. ${ }^{16-18}$ Further, because human genetic variation is gradual, many individuals have characteristics from two or more continental groups. ${ }^{19}$ Thus, the genetically based "biogeographical ancestry" assigned to any given person generally is broadly distributed and accompanied by sizable uncertainties. ${ }^{19}$ Although genetic analyses of large numbers of loci can estimate the percentage of a person's ancestors coming from various popula-

$\overline{\text { Received on } 16.06 .2015}$

Approved by the Advisory Board and accepted for publication on 20.02.2016

* Study conducted at the Juarez Hospital - Mexico City, Mexico.

Financial support: none.

Conflict of interest: none.

\footnotetext{
Department of Dermatology, Juarez Hospital - Mexico City, Mexico.

Department of Dermatology, University of Chile - Santiago de Chile, Chile.

Department of Dermatology, Emory University School of Medicine, Atlanta, GA USA.

Department of Dermatology, Universidad Central de Venezuela - Caracas, Venezuela.

Department of Dermatology, University of Buenos Aires - Buenos Aires, Argentina.
}

C2017 by Anais Brasileiros de Dermatologia 
tions, these estimates may assume a false distinctiveness of parental populations, since human groups have exchanged mates from local to continental scales throughout history. ${ }^{20-23}$ So strict, deep genetic analysis suggests there are not pure human races.

\section{SKIN COLOR}

While many physical characteristics are commonly distributed within and among groups, skin color is somewhat different. $\underline{24} \underline{25}$ This attribute is important to dermatology because it affects presentation and management of many cutaneous diseases. ${ }^{1,}{ }^{26} \mathrm{Ap}-$ proximately $10 \%$ of the variance in skin color occurs within racial/ genetic groups, and $90 \%$ occurs between groups. $\frac{27}{}$ Distribution of skin color and its geographic patterning - e.g., darker skin near the equator - indicates that skin color has been under strong selective pressure throughout human history. $\underline{28-30}$ Darker skin is selected in equatorial regions to prevent sunburn, skin cancer, photolysis of folate, and damage to sweat glands. $\underline{28}, \underline{29}$ Selection of light skin in higher latitudes may enable the body to form greater amounts of vitamin $\mathrm{D}$, preventing rickets; alternatively, regional lighter skin may correspond simply to an absence of selection for dark skin. 30,31

Because of selective pressure, similar skin colors can result from convergent adaptation rather than from genetic relatedness. Sub-Saharan Africans, tribal populations from southern India, Australian Aborigines and many groups of Amerindians have similar skin pigmentation, but genetically they are no more similar than other widely separated groups. .32 In areas where people from different regions have extensively mixed, the connection between skin color and ancestry has been substantially weakened..$^{32}$ In Brazil, for example, genetic analysis has shown that skin color is not closely associated with the percentage of recent African ancestors. $\cdot \underline{3}$

Skin color is not specific to a racial group and the cutaneous biology of pigmentation processes such as post-inflammatory hyperpigmentation $(\mathrm{PIH})$ is very similar in populations with distinct

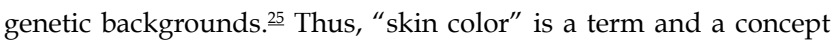
that is relevant to cutaneous biology and disease research, independent of racial background.

\section{RACE AND ETHNICITY}

When problems surrounding the word "race" became increasingly apparent during the 20th century, the word "ethnicity" was promoted as a way of characterizing the differences between groups. $\frac{34,35}{3}$ Ethnicity emphasizes the cultural, socioeconomic, religious, and political qualities of humans rather than genetic ancestry. It may encompass language, diet, religion, dress, customs, or historical identity. $\stackrel{34}{35}$ However, as a way of understanding human groups, ethnicity suffers from several shortcomings. First, ascribing an ethnic identity to a group can imply a greater degree of uniformity than it really exists. In the United States, the ethnic group "Hispanic or Latino" contains subgroups such as Cuban Americans, Mexican Americans, Puerto Ricans, and recent immigrants from Central America..$^{\frac{36}{6}}$ Combining these groups into a single category may serve useful bureaucratic ends but does not improve understanding for medical research. Ethnic groups can share a common ancestral origin that also can be a defining characteristic of a racial group. $\frac{37}{}$ Furthermore, ethnic groups tend to promote marriage within the group, which creates an expectation of biological cohesion regardless of whether that cohesion existed in the past. ${ }^{34}, \underline{35} \mathrm{Fi}-$ nally, despite attempts to distinguish "ethnicity" from "race", the two terms often are used interchangeably. $\underline{\underline{38}}$

\section{CATEGORIZING BY ANCESTRY}

An alternative grouping schema in genetic research is to categorize individuals by ancestry. Ancestry may be defined geographically (e.g., Asian, sub-Saharan African, or northern European), geopolitically (e.g., Vietnamese, Zambian, or Norwegian), or culturally (e.g., Brahmin, Lemba, or Apache). $\frac{39}{}$ The definition of ancestry may recognize a single predominant source or multiple sources. $\stackrel{40}{ }$ Ancestry can be ascribed to an individual by an observer, as was the case with the US census prior to 1960; it can be identified from a list of possibilities or with use of terms drawn from that person's experience; or it can be calculated from genetic data by use of loci with allele frequencies that differ geographically. Estimates of biogeographical ancestry generally agree with self-assessed ancestry among participants in biomedical research. .11 However, some individuals are not knowledgeable about their ancestral backgrounds. ${ }^{42}, 43$ In one series of focus groups in the state of Georgia, $40 \%$ of respondents said they did not know one or more of their four grandparents well enough to be certain how that person(s) would identify racially. ${ }^{44}$ Miss-attributed paternity or adoption can separate biogeographical ancestry from socially defined ancestry. Furthermore, the exponentially increasing number of our ancestors makes ancestry a quantitative, rather than qualitative, trait -5 centuries (or 20 generations) ago, each person had a maximum of 11 million ancestors. $\frac{45}{}$ To complicate matters further, recent analyses suggest that everyone living today has exactly the same set of genealogical ancestors who lived as recently as a few thousand years in the past, although we have received our genetic inheritance in different proportions from those ancestors. .40 In the end, the terms "race," "ethnicity," and "ancestry" describe just a small part of the complex web of biological and social connections that link individuals and groups to each other.

\section{GENETIC BACKGROUND AND DISEASE}

Racial and ethnic groups can exhibit substantial average differences in disease incidence, disease severity, disease progression, and response to treatment. ${ }^{46}$ In the United States, African Americans have higher rates of mortality compared with other racial or ethnic groups for 8 of the top 10 causes of death..$^{47}$ U.S. Latinos have higher rates of death from diabetes, liver disease, and infectious diseases than non-Latinos. $\stackrel{48}{ }$ Native Americans suffer from higher rates of diabetes, tuberculosis, pneumonia, influenza, and alcoholism versus the rest of the U.S. population. ${ }^{49}$ European Americans die more often from heart disease and cancer than do Native Americans, Asian Americans, or Hispanics. $\underline{47}$

Why is this? Considerable evidence indicates that the racial and ethnic health disparities observed in the United States are primarily due to the effects of discrimination, access to care, health-related behaviors, racism, and other socially mediated forces. $\frac{50,51}{\text { The }}$ child mortality rate for African Americans is approximately twice the rate for European Americans, but a study that evaluated births among these two groups in the military (with care provided through the same medical system) showed equivalent child mortality rates. .50 Further, recent immigrants from Mexico to the United States have better indicators on some health measures than do Mexican Americans who are more assimilated into American culture. 1 Diabetes 
and obesity are more common among Native Americans living in U.S. reservations than among those living outside reservations. $\underline{\underline{52}}$ Rates of heart disease among African Americans are associated with the segregation patterns in the neighborhoods where they live. $\underline{\underline{53}}$ It is clear that the risks for many diseases are elevated in socially, economically, and politically disadvantaged groups in the United States, suggesting that socioeconomic inequities are responsible for a substantial proportion of the variability in health patterns..$\underline{54}$

However, differences in allele frequencies certainly contribute to group differences in the incidence of some monogenic diseases, and they may contribute to differences in the incidence of some common diseases. $.5,55,56$ For the monogenic diseases, the frequency of causative alleles usually correlates best with ancestry, whether familial (for example, Ellis-van Creveld syndrome among the Pennsylvania Amish), ethnic (Tay Sachs disease among Ashkenazi Jewish populations), or geographical (hemoglobinopathies among people with ancestors who lived in malarial regions). $. \underline{15}, \underline{55}, \underline{56}$

To the extent that ancestry corresponds with racial or ethnic groups, the incidence of monogenic diseases can differ between groups categorized by race or ethnicity, and healthcare professionals typically take these patterns into account in making diagnoses. 57,58 Even with common diseases involving numerous genetic variants and environmental factors, data suggest the involvement of differentially distributed alleles with small to moderate effects. Frequently cited examples include hypertension,,$\underline{57}$ diabetes, obesity, and prostate cancer. $\stackrel{58-60}{-}$ However, in none of these cases has allelic variation in a susceptibility gene been shown to account for a significant fraction of the difference in disease prevalence among groups, and the role of genetic factors in generating these differences remains uncertain.

\section{RELEVANCE TO SKIN DISEASE: EXAMPLE OF ACNE}

Acne occurs in people of all ethnicities, races, and colors of skin; however, the manifestations, especially severity, can be different in various population groups. ${ }^{1,62}$ For example, in 2002 Cordain published a study of non-westernized populations in the Polynesia and South America showing the almost total absence of acne in these primitive groups. $\frac{63}{} \mathrm{He}$ attributed the lack of acne to a non-Western diet high in nutrients, but genetic variations may also contribute. $\underline{63}$

There are few data about how acne manifests in different populations, but based on literature and on our experience, we propose some recommendations for terminology (Table 1). Epidemiol- ogy and treatment options may vary, and acne sequelae are different in darker skin due to an elevated risk of hyperpigmentation, keloid scars development, tolerance variations to topical medication and metabolic response to systemic isotretinoin. .64 Epigenetics - changes in phenotype or gene expression due to environmental factors - may have a role in the manifestation of acne in particular cultures and/or populations. Finally, cultural attitudes may have an impact on treatment success (for example, some cultures consider acne a normal part of growing up rather than a treatable disease), and should be considered by the clinician. $\underline{6,}, \underline{6}$

The issue is to have the tools to correlate the genetic background and skin color with disease characteristics. One suggestion is to use a scale to classify skin color and otherwise use general ethnic or racial ancestry by physical phenotype and social history. ${ }^{1,67}$ As a proposal for studies in Latin America, terminology for races could include Latin- American caucasian, Amerindian, Mestizo, Afro-Latin-American, and Latin american- Asian Mongolian. Other racial mixtures that occur less frequently, like "Mulattos" (a combination between African and Caucasian), can be categorized as "Other." Although this system has limitations, it is a practical approach for the study of cutaneous diseases like acne in the absence of sophisticated genetic studies.

Several clinically relevant skin classification systems have been developed and may be useful. 24, 26, $\underline{68-70}$ The well-known Fitzpatrick skin phototype scale ranks skin according to response to UV exposure. $\frac{70}{}$ Individuals with skin of color or ethnic skin often have Fitzpatrick skin phototypes IV, V, and VI. However, the phototype designation has been shown to have only a weak correlation with skin color. $\underline{71} \underline{72}$ The Taylor Hyperpigmentation Scale $\underline{24}$ is a visual scale with a precise system to indicate skin color and pigmentation. While it can be used easily in clinical practice, an initial study of its application showed significant inter-individual variability among dermatologists in ratings of both skin hue $(\mathrm{P}<0.0001)$ and pigmentation $(\mathrm{P}=0.0008) . \underline{63}$ Notably, variability was more common when the scale was applied to individuals who had very light or very dark skin hues. $\stackrel{24}{\underline{63}}$ The authors propose that the scale can be useful for an individual clinician to assess skin color and changes in a given patient over time. $\underline{\underline{63}}$

Lancer formulated an ethnicity scale that includes both skin phototype and racial background with the goal of anticipating patients' responses to laser resurfacing treatments (Table 2A). $\frac{73}{}$ Goldman has developed a refinement of this system that includes both

\section{TABLE 1: Recommendations for terminology}

\section{Term}

Recommended Skin of color

Not Recommended

1) Ethnic skin

2) Hispanic skin

3) Asian skin

Reason for Recommendation

- Relates to biology of pigmented skin

- More descriptive than racial/ethnic terms that are not related to skin traits

- Non-specific term encompassing all non-Caucasian skin

- Does not relate to genetic heritage

- Does not give information on skin type, tone, or characteristics

- Denotes Spanish-speaking ability and/or localization to South and Central America

- Does not give information on skin type, tone, or characteristics

- General term for people living in or from geographic area (Asia) that includes $60 \%$ of the world's population

- Does not give information on skin type, tone, or characteristics 
TABLE 2: Lancer ethnicity scale (A) and Goldman world classification scale (B) reprinted with permission

A)

\section{Geography}

African background

Central East, West African

Eritrean and Ethiopian

North African, Middle East

Arabian background

Sephardic Jewish

Asian background

Chinese, Korean, Japanese, Thai,

Vietnamese

Filipino, Polynesian

European background

Ashkenazi Jewish

Celtic

Central Eastern European

Nordic

Northern European (general)

Southern European, Mediterranean

Latin/Central/South American background

Central/South American Indian

North American background

Native American (including Inuit)
B)

European/Cauca-

sian - white

$\begin{array}{ll}\text { Skin Type } & \text { Type } \\ \text { V } & 5 \\ \text { V } & 5 \\ \text { V } & 5\end{array}$

III 4

IV

IV

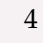

4

$\begin{array}{ll}\text { II } & \\ \text { I } & 3 \\ \text { III } & 1 \\ \text { I-II } & 2 \\ \text { I } & 1 \\ \text { III } & \text { I }\end{array}$

III

IV

Asian - yellow

Arabian/Mediterranean/Hispanic - light brown

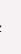

(1)

(1)

1-2

3-4 Indian - brown

IV

\section{4}

II

3

African - black a) Pale, cannot tan, burns easily, no post inflammatory pigmentation

b) Tan, rarely burns, rarely develops post inflammatory pigmentation

c) Deep tan, never burns, develops post inflammatory pigmentation

a) Pale, cannot tan, burns easily, no post inflammatory pigmentation

b) Tan, rarely burns, rarely develops post inflammatory pigmentation

c) Deep tan, never burns, develops post inflammatory pigmentation

a) Pale, cannot tan, burns easily, no post inflammatory pigmentation

b) Tan, rarely burns, rarely develops post inflammatory pigmentation

c) Deep tan, never burns, develops post inflammatory pigmentation

a) Pale, cannot tan, burns easily, no post inflammatory pigmentation

b) Tan, rarely burns, rarely develops post inflammatory pigmentation

c) Deep tan, never burns, develops post inflammatory pigmentation a) Pale, cannot tan, burns easily, no post inflammatory pigmentation

b) Tan, rarely burns, rarely develops post inflammatory pigmentation

c) Deep tan, never burns, develops post inflammatory pigmentation

Source: Lancer HA, 1998. 73 and Shiffman MA, et al, 2008. 74

geographic/racial backgrounds, response to UV light, and potential for hyperpigmentation following procedures (Table 2). $\stackrel{74}{ }$ Of the available tools, it seems that a combination of the Fitzpatrick skin phototype and the Taylor hue may provide clinical information that can be relevant to treatment. In the case of acne and its correlation with skin color studies, the simplest tool is the Fitzpatrick scale and alternatively the Taylor scale of skin colors, correlated with the ethnic division suggested above.

\section{REFERENCES}

1. Taylor SC. Epidemiology of skin diseases in ethnic populations. Dermatol Clin. 2003;21:601-7.

2. Lander ES, Linton LM, Birren B, Nusbaum C, Zody MC, Baldwin J, et al. Initial sequencing and analysis of the human genome. Nature. 2001;409:860-921.

3. International HapMap Consortium. The International HapMap Project. Nature. 2003;426:789-96.

4. Bagatin E, Kamamoto CS, Guadanhim LR, Sanudo A, Dias MC, Barraviera IM, et al. Prevalence of acne vulgaris in patients with Down syndrome. Dermatology. 2010;220:333-9.

5. Tishkoff SA, Verrelli BC. Patterns of human genetic diversity: implications for human evolutionary history and disease. Annu Rev Genomics Hum Genet. 2003;4:293-340.

\section{CONCLUSIONS}

Because acne is a worldwide disease that occurs in virtually all known races and ethnicities, it is important to understand whether there are differences in its manifestation. Vague terminology such as "ethnic skin" and "Hispanic skin" compound the problem of sparse data; the term "skin of color" should be used in favor of nonspecific descriptors. We hope the future will provide population-based data to help elucidate whether acne is the same in all peoples.
6. Tishkoff SA, Williams SM. Genetic analysis of African populations: human evolution and complex disease. Nat Rev Genet. 2002;3:611-21.

7. Ingman M, Kaessmann H, Pääbo S, Gyllensten U. Mitochondrial genome variation and the origin of modern humans. Nature. 2000;408:708-13.

8. Underhill PA, Shen P, Lin AA, Jin L, Passarino G, Yang WH, et al. Y chromosome sequence variation and the history of human populations. Nat Genet. 2000;26:358-61.

9. Kaessmann $\mathrm{H}$, Heissig $F$, von Haeseler $A$, Paabo S. DNA sequence variation in a non-coding region of low recombination on the human $\mathrm{X}$ chromosome. Nat Genet. 1999 May;22:78-81.

10. Harpending $\mathrm{H}$, Rogers $\mathrm{A}$. Genetic perspectives on human origins and differentiation. Annu Rev Genomics Hum Genet. 2000;1:361-85.

11. Satta Y, Takahata N. Out of Africa with regional interbreeding? Modern human 
origins. Bioessays. 2002;24:871-5.

12. Tishkoff SA, Pakstis AJ, Stoneking M, Kidd JR, Destro-Bisol G, Sanjantila A, et al. Short tandem-repeat polymorphism/alu haplotype variation at the PLAT locus: implications for modern human origins. Am J Hum Genet. 2000;67:901-25.

13. Stringer C. Modern human origins: progress and prospects. Philos Trans R Soc Lond B Biol Sci. 2002;357:563-79.

14. Wall JD. Detecting ancient admixture in humans using sequence polymorphism data. Genetics. 2000;154:1271-9.

15. Risch N, Burchard E, Ziv E, Tang H. Categorization of humans in biomedical research: genes, race and disease. Genome Biol. 2002;3:comment2007.

16. King MC, Motulsky AG. Human genetics. Mapping human history. Science. 2002;298:2342-3.

17. Calafell F. Classifying humans. Nat Genet. 2003;33:435-6.

18. Tishkoff SA, Kidd KK. Implications of biogeography of human populations for 'race' and medicine. Nat Genet. 2004;36:S21-7.

19. Pfaff CL, Barnholtz-Sloan J, Wagner JK, Long JC. Information on ancestry from genetic markers. Genet Epidemiol. 2004;26:305-15.

20. Shriver MD, Parra EJ, Dios S, Bonilla C, Norton H, Jovel C, et al. Skin pigmentation, biogeographical ancestry and admixture mapping. Hum Genet. 2003;112:387-99.

21. Bamshad M, Wooding S, Salisbury BA, Stephens JC. Deconstructing the relationship between genetics and race. Nat Rev Genet. 2004;5:598-609.

22. Cavalli-Sforza LL MP, Piazza A The history and geography of human genes. Princeton, NJ: Princeton University Press; 1994.

23. Dirk Hoerder. Cultures in contact: world migrations in the second millennium. Durham, NC: Duke University Press; 2002.

24. Taylor SC, Arsonnaud S, Czernielewski J; Hyperpigmentation Scale Study Group. The Taylor Hyperpigmentation Scale: a new visual assessment tool for the evaluation of skin color and pigmentation. Cutis. 2005;76:270-4.

25. Ortonne JP. Normal and abnormal skin color. Ann Dermatol Venereol. 2012 ;139:S125-9.

26. Taylor SC. Epidemiology of skin diseases in people of color. Cutis. 2003;71:271-5.

27. Relethford JH. Apportionment of global human genetic diversity based on craniometrics and skin color. Am J Phys Anthropol. 2002;118:393-8.

28. Sturm RA, Teasdale RD, Box NF. Human pigmentation genes: identification, structure and consequences of polymorphic variation. Gene. 2001;277:49-62.

29. Rees JL. Genetics of hair and skin color. Annu Rev Genet. 2003;37:67-90.

30. Jablonski NG. The evolution of human skin colouration and its relevance to health in the modern world. J R Coll Physicians Edinb. 2012;42:58-63.

31. Harding RM, Healy E, Ray AJ, Ellis NS, Flanagan N, Todd C, et al. Evidence for variable selective pressures at MC1R. Am J Hum Genet. 2000;66:1351-61.

32. Parra EJ, Kittles RA, Shriver MD. Implications of correlations between skin color and genetic ancestry for biomedical research. Nat Genet. 2004;36:S54-60.

33. Parra FC, Amado RC, Lambertucci JR, Rocha J, Antunes CM, Pena SD. Color and genomic ancestry in Brazilians. Proc Natl Acad Sci U S A. 2003;100:177-82.

34. Huxley J HA. We Europeans: a survey of racial problems. New York: Harper; 1936.

35. Hutchinson J, Smith AD, editors. Ethnicity. New York: Oxford University Press; 1996.

36. Hayes-Bautista DE, Chapa J. Latino terminology: conceptual bases for standardized terminology. Am J Public Health. 1987;77:61-8.

37. Cornell S HD. Ethnicity and Race. Making Identities in a Changing World. Thousand Oaks, CA: Pine Forge Press; 1998.

38. Oppenheimer GM. Paradigm lost: race, ethnicity, and the search for a new population taxonomy. Am J Public Health. 2001;91:1049-55.

39. Elliott C, Brodwin P. Identity and genetic ancestry tracing. BMJ. 2002;325:1469-71.

40. Rohde DL, Olson S, Chang JT. Modelling the recent common ancestry of all living humans. Nature. 2004;431:562-6.

41. Tang H, Quertermous T, Rodriguez B, Kardia SL, Zhu X, Brown A, et al. Genetic structure, self-identified race/ethnicity, and confounding in case-control association studies. Am J Hum Genet. 2005;76:268-75.

42. Brodwin P. Genetics, identity, and the anthropology of essentialism. Anthropological Quarterly. 2002;75:323-30.

43. Kaplan EA . Black like I thought I was. LA Weekly. Voice Media Group; Los Angeles; 2003

44. Condit C, Templeton A, Bates BR, Bevan JL, Harris TM. Attitudinal barriers to delivery of race-targeted pharmacogenomics among informed lay persons. Genet Med. 2003;5:385-92

45. Ohno S. The Malthusian parameter of ascents: what prevents the exponential increase of one's ancestors? Proc Natl Acad Sci U S A. 1996;93:15276-8.

46. TA L. Why we should continue to study race.but do a better job: an essay on race, racism and health. Ethn Dis. 1996;6:21-9.

47. Hummer RA BM, Rogers RG. Critical perspectives on racial and ethnic differences in health in later life. Washington, DC: National Academy Press; 2004.
48. Vega WA, Amaro H. Latino outlook: good health, uncertain prognosis. Annu Rev Public Health. 1994;15:39-67.

49. Mahoney MC, Michalek AM. Health status of American Indians/Alaska Natives: general patterns of mortality. Fam Med. 1998;30:190-5.

50. Rawlings JS, Weir MR. Race- and rank-specific infant mortality in a US military population. Am J Dis Child. 1992;146:313-6.

51. Franzini L, Ribble JC, Keddie AM. Understanding the Hispanic paradox. Ethn Dis. 2001;11:496-518.

52. Cooper RS, Rotimi CN, Kaufman JS, Owoaje EE, Fraser H, Forrester T, et al. Prevalence of NIDDM among populations of the African diaspora. Diabetes Care. 1997;20:343-8

53. Fang J, Madhavan S, Bosworth W, Alderman MH. Residential segregation and mortality in New York City. Soc Sci Med. 1998;47:469-76.

54. Cooper RS, Kaufman JS, Ward R. Race and genomics. N Engl J Med. 2003:348:1166-70.

55. Burchard EG, Ziv E, Coyle N, Gomez SL, Tang H, Karter AJ, et al. The importance of race and ethnic background in biomedical research and clinical practice. $N$ Engl J Med. 2003;348:1170-5.

56. Tate SK, Goldstein DB. Will tomorrow's medicines work for everyone? Nat Genet. 2004;36:S34-42.

57. Douglas JG, Thibonnier M, Wright JT Jr. Essential hypertension: racial/ethnic differences in pathophysiology. J Assoc Acad Minor Phys. 1996;7:16-21.

58. Gower BA, Fernández JR, Beasley TM, Shriver MD, Goran MI. Using genetic admixture to explain racial differences in insulin-related phenotypes. Diabetes. 2003;52:1047-51.

59. Fernández JR, Shriver MD, Beasley TM, Rafla-Demetrious N, Parra E, Albu J, et al. Association of African genetic admixture with resting metabolic rate and obesity among women. Obes Res. 2003;11:904-11.

60. Platz EA, Rimm EB, Willett WC, Kantoff PW, Giovannucci E. Racial variation in prostate cancer incidence and in hormonal system markers among male health professionals. J Natl Cancer Inst. 2000;92:2009-17.

61. Mountain JL, Risch N. Assessing genetic contributions to phenotypic differences among 'racial' and 'ethnic' groups. Nat Genet. 2004;36:S48-53.

62. Halder RM, Brooks HL, Callender VD. Acne in ethnic skin. Dermatol Clin. 2003:21:609-15, vii.

63. Cordain L, Lindeberg S, Hurtado M, Hill K, Eaton SB, Brand-Miller J. Acne vulgaris: a disease of Western civilization. Arch Dermatol. 2002;138:1584-90.

64. Callender VD. Acne in ethnic skin: special considerations for therapy. Dermatol Ther. 2004; 17:184-95

65. Pawin H, Chivot M, Beylot C, Faure M, Poli F, Revuz J, et al. Living with acne. A study of adolescents' personal experiences. Dermatology. 2007;215:308-14.

66. Poli F, Auffret N, Beylot C, Chivot M, Faure M, Moyse D, et al. Acne as seen by adolescents: results of questionnaire study in 852 French individuals. Acta Derm Venereol. 2011;91:531-6.

67. Taylor SC, Cook-Bolden F, Rahman Z, Strachan D. Acne vulgaris in skin of color. J Am Acad Dermatol. 2002;46:S98-106.

68. Chan JL, Ehrlich A, Lawrence RC, Moshell AN, Turner ML, Kimball AB. Assessing the role of race in quantitative measures of skin pigmentation and clinical assessments of photosensitivity. J Am Acad Dermatol. 2005;52:609-15.

69. Baumann L, Rodriguez D, Taylor SC, Wu J. Natural considerations for skin of color. Cutis. 2006;78:2-19.

70. Fitzpatrick TB. The validity and practicality of sun-reactive skin types I through VI. Arch Dermatol. 1988 Jun;124(6):869-71.

71. Rubegni P, Cevenini G, Flori ML, Fimiani M, Stanghellini E, Molinu A, et al. Relationship between skin color and sun exposure history: a statistical classification approach. Photochem Photobiol. 1997;65:347-51.

72. Yun IS, Lee WJ, Rah DK, Kim YO, Park BY. Skin color analysis using a spectrophotometer in Asians. Skin Res Technol. 2010;16:311-5.

73. Lancer HA. Lancer Ethnicity Scale (LES). Lasers Surg Med. 1998;22:9.

74. Shiffman MA, Mirrafati S, Lam SM. Simplified facial rejuvenation. Berlin; New York: Springer; 2008.

MAILING ADDRESS:

Vicente Torres, $M D$

Juarez Hospital

Olmo \#62 M Jardines de Santa Monica

Tialnepantla 54050

Edo De Mexico, Mexico

Email:drvicente_2006@yahoo.com.mx

How to cite this article: Torres V, Herane MI, Costa A, Piquero Martin J, Troielli T, Sanders V. Refining the ideas of "ethnic" skin. An Bras Dermatol. 2017;92(2):221-5. 